\title{
8 | 2019
}

64. Jahrgang

20. April 2019

S. $273-320$

PVSt 1062

Zeitschrift für deutsches, europäisches

\section{Die Aktiengesellschaft} und internationales Aktien-, Unternehmensund Kapitalmarktrecht

Herausgegeben von Prof. Dr. Heinz-Dieter Assmann und Prof. Dr. Mathias Habersack

die-aktiengesellschaft.de

in Verbindung mit VorsRiBGH Prof. Dr. Ingo Drescher · Prof. Dr. Volker Emmerich ·

VizepräsBVerfG Prof. Dr. Stephan Harbarth · Prof. Dr. Jens Koch · Prof. Dr. Hans-Joachim Mertens

Prof. Dr. Dr. h.c. Uwe H. Schneider · RA Prof. Dr. Jochen Vetter · Prof. Dr. Dr. h.c. Wolfgang Zöllner

Beratermodul AG
Aufsätze > Jens Koch - Die Ad-hoc-Publizität: Veröffentlichungs- oder Wissens-

organisationspflicht? 273

Richard Backhaus / Tobias Brouwer - Zustimmungsvorbehalte des Aufsichtsrats bei Geschäften mit nahestehenden Personen (Related Party Transactions) bei der KGaA - HGB sticht AktG

Kommentar > Daniel Schubmann /Stefan Hubertus Tolksdorf - Die Vertretung der AG bei Unternehmenstransaktionen mit (zukünftigen) Vorstandsmitgliedern - Kommentar zu BGH v. 15.1.2019 - II ZR 392/17, AG 2019, 298

Rechtsprechung > Aktienrecht: Vertretung der AG bei Rechtsgeschäften mit einer $\mathrm{GmbH}$, deren alleiniger Gesellschafter ein Vorstandsmitglied ist (BGH, Urt. v. 15.1.2019 - II ZR 392/17) 298

Aktienrecht: Verteilung der Gerichtskosten in Beschwerdeverfahren über die Zusammensetzung des Aufsichtsrats (OLG Stuttgart, Beschl. v. 20.8.2018 - 20 W 21/18)

Societas Europaea: Zusammensetzung des Verwaltungsrats einer Europäischen Aktiengesellschaft, Verbot der Schlechterstellung (LG Frankfurt/M., Urt. v. 3.5.2018 - 3-05 0 101/17, nrkr.)

Rechts-Report

Stefan Mutter - Leitlinien der EU Kommission zur Vergütungs-

berichterstattung nach ARUG II vor der Türe

Walter Bayer / Thomas Hoffmann - Beschlussmängelklagen-

Monitor 2017/2018 

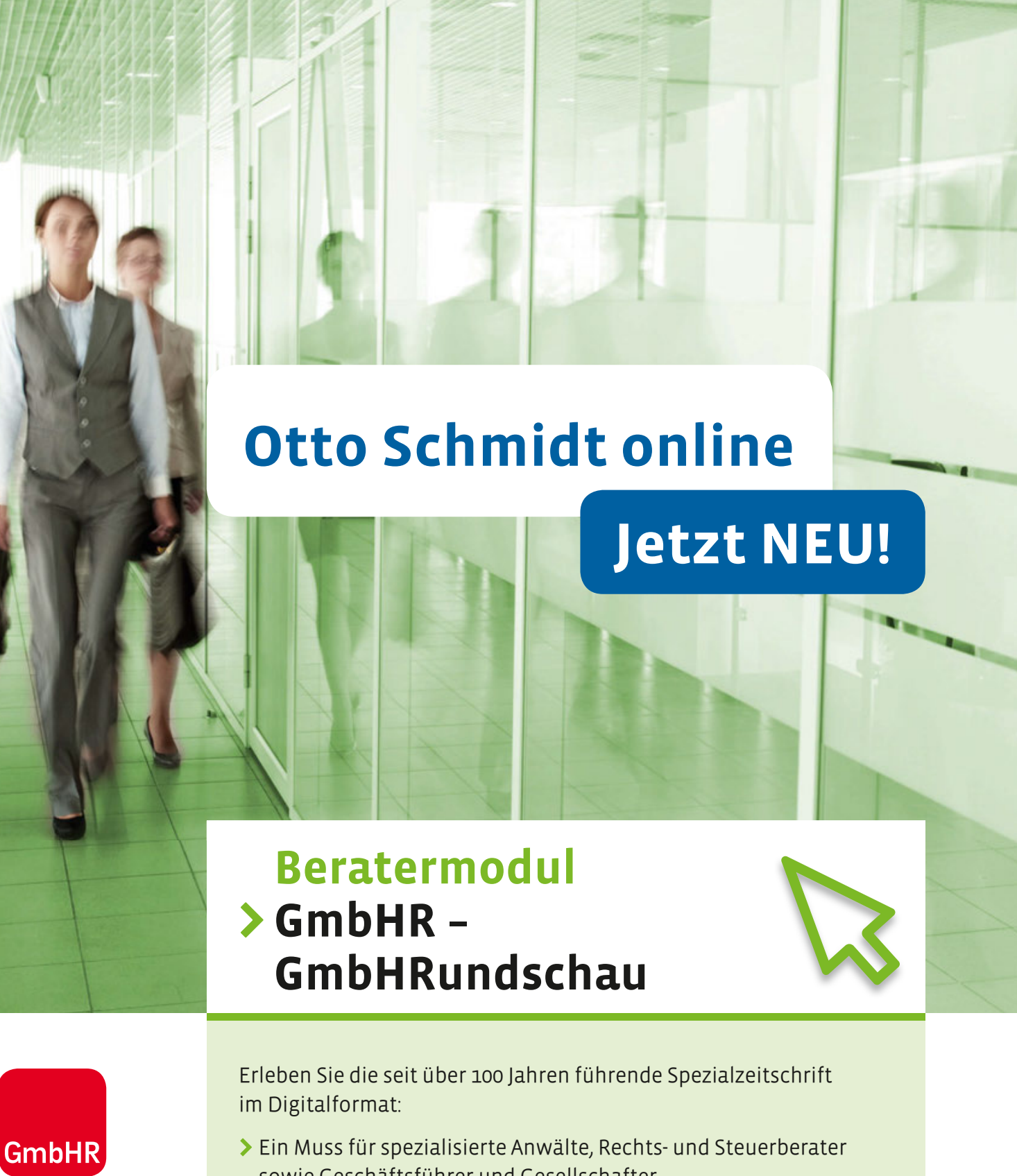

Erleben Sie die seit über 100 Jahren führende Spezialzeitschrift im Digitalformat:

$>$ Ein Muss für spezialisierte Anwälte, Rechts- und Steuerberater sowie Geschäftsführer und Gesellschafter

$>$ Gezielter Direktzugriff auf sämtliche Inhalte seit 1991

$>$ Praktisch, zitierfähig und rechtssicher

$>$ Aktuelle Fachbeiträge und fachkundige Kommentare zu aktuellen Entscheidungen

$>$ Inklusive Selbststudium mit Zertifikat nach § 15 FAO

Nur 26,- $€$ monatlich für 3 Nutzer. Zzgl. MwSt. Auch im Aktionsmodul Gesellschaftsrecht enthalten.

\section{Jetzt 4 Wochen gratis nutzen!}

www.otto-schmidt.de/gmbhr 